\title{
Determinación sociohistórica y literal de La ciudad y los perros (1963) de Mario Vargas Llosa ${ }^{1}$
}

\author{
Determinação sócio-histórica e literal Da cidade e dos cães (1963) por Mario Vargas Llosa \\ Sociohistorical and literal determination of The city and dogs (1963) by Mario Vargas Llosa \\ Jesús Miguel Delgado Del Aguila (1) \\ Universidad Tecnológica del Perú (UTP), Lima, Perú.
}

\begin{abstract}
RESUMEN
En primer lugar, se hará una breve descripción del contexto histórico y político sobre esta novela; para ello, se tendrán en cuenta algunas acotaciones que aluden a la situación, no solo nacional, sino mundial. Como segundo apartado, se sostendrán las ideologías política y filosófica que se presentan en ese mismo contexto. El tercer tema argumenta una resumida información en función del boom latinoamericano (definición, técnicas y representantes), junto a una mención vinculada con los aportes que estaría brindando Vargas Llosa a la Literatura. El cuarto tópico implica la presentación misma de La ciudad y los perros (1963), la cual se propondrá en ese apartado tan solo con una visión general y sintética de su contenido. El quinto abarca la recepción crítica de esta obra; es decir, la hermenéutica o los estudios realizados en torno a esta novela, en la que se distinguen los temas reincidentes. Estos cinco primeros tópicos servirían para la formación de un marco panorámico sobre el autor y el estudio que ha hecho la crítica literaria en función de la novela analizada.
\end{abstract}

Palabras clave: Contexto histórico. Boom latinoamericano. Análisis literario. Sociedad. Fenomenología. Existencialismo.

\begin{abstract}
RESUMO
Em primeiro lugar, será feita uma breve descrição do contexto histórico e político desta novela; para isso, serão consideradas algumas dimensões que aludem à situação, não apenas nacional, mas mundial. Como segunda seção, as ideologias políticas e filosóficas que são apresentadas nesse mesmo contexto serão sustentadas. O terceiro tópico discute uma informação resumida com base no boom latino-americano (definição, técnicas e representantes), juntamente com uma menção relacionada às contribuições que Vargas Llosa ofereceria à literatura. $\mathrm{O}$ quarto tópico envolve a apresentação Da cidade e dos cães (1963), que será proposto nessa seção com apenas uma visão geral e sintética de seu conteúdo. O quinto cobre a recepção crítica deste trabalho; isto é, a hermenêutica ou os estudos realizados em torno desta novela, em que os assuntos recidivistas são distinguidos. Esses cinco primeiros tópicos serviriam para formar um quadro panorâmico sobre o autor e o estudo que a crítica literária fez com base no romance analisado. Palavras-chave: Contexto histórico. Boom latino-americano. Análise literária. Sociedade. Fenomenologia. Existencialismo
\end{abstract}

\begin{abstract}
In the first place, a brief description of the historical and political context of this novel will be made; for this, some dimensions will be taken into account that allude to the situation, not only national, but worldwide. As a second section, the political and philosophical ideologies that are presented in that same context will be sustained. The third topic argues a summary information based on the Latin American boom (definition, techniques and representatives), together with
\end{abstract}

\footnotetext{
1 El siguiente artículo forma parte de mi tesis inédita de licenciatura, titulada Protagonismo violento y modos de representación en La ciudad y los perros (1963), financiada por la Universidad Nacional Mayor de San Marcos (Lima-Perú), a través del Fondo de Promoción de Trabajo de Tesis de Pregrado (2012) del VRI-UNMSM. La última versión se terminó de elaborar en el 2017. Este trabajo de investigación recibió el asesoramiento del Dr. Marco Gerardo Martos Carrera y se sustentó el 18 de marzo del mismo año. Por la publicación del artículo, recibiré un incentivo económico de la Universidad Tecnológica del Perú (UTP/Lima-Perú).
} 
a mention related to the contributions that Vargas Llosa would be offering to Literature. The fourth topic involves the presentation of The city and dogs (1963), which will be proposed in that section with only a general and synthetic overview of its content. The fifth covers the critical reception of this work; that is to say, the hermeneutics or the studies carried out around this novel, in which the recurrent themes are distinguished. These first five topics would serve to form a panoramic frame on the author and the study that literary criticism has done based on the analyzed novel.

Keywords: Historic context. Latin American boom. Literary analysis. Society. Phenomenology. Existentialism.

\section{El contexto histórico y social}

Erich Auerbach en su libro Mímesis (1996) señala que es importante conocer la historia para hacer las descripciones correspondientes sobre un hecho literario; es en ese momento, recién, en el que se puede hacer una mera interpretación correlativa a la historia de una sociedad, tomando el contexto como base o eje. En este caso, la historia de la violencia y la literatura que le correspondería a Perú entre los años de 1960 está vinculada con lo acontecido en Latinoamérica y Occidente en sus diversas cuestiones históricas y sociales; por ello, mencionaré algunos sucesos históricos de relevancia en la historia mundial, de los países de Cuba, EE. UU., China, Argentina, Israel, Bolivia y Francia. Luego indicaré algunos datos importantes en función de lo que ocurrió en la historia del Perú durante ese período y las consecuencias que atravesó por los sucesos históricos de EE. UU. y Cuba.

En primer lugar, en Cuba, se empiezan a notar los cambios políticos y sociales producidos por la Revolución, que finalizó en 1959. Pero, dos años después ${ }^{2}$, transitan por un intento fallido de posesionarse de la Bahía de Cochinos, al mando de cubanos exiliados y norteamericanos, quienes fueron derrotados por miembros de las Fuerzas Armadas Revolucionarias (FAR) de Cuba. Este suceso generaría un enfrentamiento entre el bloque soviético y el capitalista, que, a su vez, sería la "crisis de los misiles" en 1962 (TENORIO, 2001), que consistió en manifestar una ley en la que se constatara el retiro de los misiles nucleares rusos de Cuba por parte de EE. UU., quien también intentaba detener el comunismo perenne en Cuba, por medio de un tratado de convivencia pacífica. En Estados Unidos, luego del asesinato del presidente norteamericano John F. Kennedy en 1963, luego de que él amenazara al mundo con una guerra nuclear un año antes, Vietnam se vuelve un objetivo militar para ellos. En 1964, EE. UU. apoya a Vietnam del Sur en su enfrentamiento contra Vietnam del Norte (este último apoyado militarmente por la Unión

\footnotetext{
2 Ese mismo año, 1961, se construye el muro de Berlín.
}

Soviética). Al siguiente año, el Ejército norteamericano bombardearía intensivamente a la población civil en Vietnam del Norte. Bajo esos mismos lineamientos, durante los sesenta, se empiezan a formar subculturas o contraculturas, que apoyan los valores humanos y pretenden que no se presencie la guerra entre Estados, bajo una manera particular y no del todo convincente, uno de estos es el movimiento hippie. Este se caracterizaba por ser de tono contestatario y proponer la liberación sexual y psicológica de sus propios instintos; aquello provocó un llamado de atención a las clases sociales. Otro movimiento contracultural que influye es el pacifismo. Este sector defendió la necesidad de desertar; es decir, no ir a luchar a Vietnam porque dicha guerra era considerada para ellos profundamente inmoral. El contexto relacionado con la guerra de Vietnam posibilitó que el pacifismo se convirtiera en uno de los más importantes movimientos contraculturales -intelectuales como Jean-Paul Sartre, Noam Chomsky, Bertrand Russell y Benjamín Spock condenaron el genocidio en Vietnam-. Uno de los refranes que empleaban era "haz el amor y no la guerra". En China (1965), Mao Tse-tung, líder del Partido Comunista (PCCh), emprende la Revolución Cultural del Proletariado. Este movimiento provocó una transformación en la sociedad china, ya que se encontraba la sociedad en conflicto y distante de su compromiso con la intervención política en sus respectivos partidos. En Argentina (1966), los militares, junto con el apoyo de distintos sectores, provocan un golpe de Estado contra, en ese entonces, el presidente Arturo Humberto Illia. En Israel (1967), acontece la Guerra de los Seis Días entre los Estados árabes vecinos, debido a la tensión que se vivía por la presencia de militares egipcios sobre las fronteras y el territorio israelíes. En Bolivia (1967), los militares asesinan al Che Guevara, un guerrillero argentino que luchaba por el ideal de libertad y las injusticias sociales. En Francia, en mayo de 1968, se produce la protesta sociocultural izquierdista de alumnos, trabajadores, obreros e intelectuales contra el poder autocrático y la imposición de una determinada modalidad de enseñanza por parte del gobierno de Charles de Gaulle. Buscaban en 
conjunto una nueva moral. Para ello, recurrieron a huelgas y revueltas estudiantiles y sindicales. Este acontecimiento también se conocerá como el Mayo francés.

En segundo lugar, el contexto que desarrolla el Perú durante los sesenta se caracteriza por tener un conflicto constante contra la desigualdad socioeconómica y cultural; a la vez, se aceptó el Gobierno militar como una solución ante el desbalance representativo que atravesaba el país (lucha de clases, en la que se distinguían los civilizados y la barbarie; además de la crítica hacia el pensamiento burgués). Lo que identificaría notoriamente el contexto, en el cual se construyó la narrativa de Mario Vargas Llosa, sería durante la dictadura del presidente Manuel Arturo Odría Amoretti, desde 1948 hasta 1956 (VILELA, 2003, p. 64), que inicia con un golpe de Estado y genera que los militares nuevamente asuman el poder, con la finalidad de distribuir las funciones que tendría la sociedad peruana. El Gobierno militar (GORRITI, 1991), al tener el poder, emplea todas las estrategias posibles para manipular y alterar las conciencias masivas; una de sus mejores tácticas es controlar y negociar con los medios de comunicación, como la prensa, la radio y la televisión (lo mismo ocurrirá con la Iglesia). Además, se emplearán las armas para imponer orden a la sociedad, puesto que se concientiza y se promete la idea de la paz y el progreso mediante esa política $^{3}$. Por otro lado, la agricultura siguió en auge hasta 1960, pero las repercusiones de la modernidad, época de la reproductibilidad técnica, no fueron convincentes para la calidad de vida que anhelaban los intelectuales y quienes pretendieron adaptarse a una economía alta. La gente andina empezará a migrar a la capital al ver que su sociedad no le satisface, que se caracteriza por los índices notorios de pobreza (con los patrones del hambre y la miseria); se obviará el conocimiento de lo que le acontece a su sociedad, sobre todo, por los intelectuales migrantes. La capital del Perú será importante en ese lapso, porque rigen la economía y las finanzas en torno al país, además de que se acrecienta su poderío industrial.

En función de las relaciones que tuvo el Perú con países extranjeros, existieron dos modalidades más directas: la de EE. UU. y la de Cuba.

El vínculo que se estableció entre EE. UU. y Perú, el cual consistió en ser dominado por el primero, la potencia mundial; con la finalidad de conseguir que el flujo de los capitales se materialice en la producción de materias primas e industrias, dentro del sector financiero. Con ello, la burguesía industrial se transformaba en un recipiente de nuevas empresas extranjeras y sus intereses nacionales comenzaban a representar las necesidades económicas

\footnotetext{
3 Con respecto al Colegio Militar Leoncio Prado, Sergio Vilela Galván (2003) cuenta que el Pdte. Manuel Prado había fundado esa escuela en el distrito porteño de La Perla (Callao), la que se conoció antiguamente como el local de la Guardia Chalaca.
}

de las empresas transnacionales que se apoderarían del Perú.

En el caso de Cuba, el contacto que tuvo con el Perú fue ideológico y mucho más indirecto, debido a la Revolución cubana (1953-1959), que repercutió en el país durante 1959, con la intención de que surgiera un nuevo tipo de sociedad no capitalista — por vez primera, un país latinoamericano había optado por otro tipo de sociedadSe adquiere la posición de izquierda, una extensa y rigurosa crítica de regímenes capitalistas y sociedades basadas en la oferta y la demanda.

\section{Las ideologías política y filosófica del contexto de La ciudad y los perros}

En el interior de La ciudad y los perros (1963), se evidencian comportamientos sociales que permiten detectar una ideología política en concordancia con los personajes que se hallan dentro de la novela, como también se muestra una ideología filosófica que se establece en la relación existente con los personajes y sus respectivas reacciones sobre los hechos.

En primer lugar, al hacer mención de ideología política, prioritariamente, se representa como contrapunto a una sociedad aburguesada por las comodidades que obtiene por pertenecer y laborar como grupo elitista sobre la ciudadanía. Téngase en cuenta que en ese período hay muchos izquierdistas y socialistas que luchan por la igualdad, la identidad, la libertad de expresión y la búsqueda de la identidad, tal como lo señala Ángel Rama (2005, p. 169-170); lo que genera un desequilibrio en la cosmovisión de los ciudadanos sobre la base de un concepto de unidad e igualdad. Por ejemplo, al mencionar a la clase política elitista, que consiste en una posición socioeconómica acomodada del Estado, se considera un afán modernizador y liberalista, del cual ha hecho alusión Enrique Bernales Ballesteros (CARRILLO, 1993), que es distintivo de las otras clases sociales, porque quien es más consumidor o adquiridor de las nuevas tecnologías o modas es, a la vez, más pulcro. Esta modernización, en general, impulsaba los proyectos de cambios socioeconómicos, políticos y culturales, puesto que se percibía un ambiente de insatisfacción en función de las nuevas demandas de la sociedad europea entre 1960 y 1970 en el Perú. Por tal motivo, los registros culturales del país se dirigieron hacia la exclusión y la marginación de la identidad (que no solo fue de carácter socioeconómico o político, sino también racial: con la distinción de blancos, cholos, mestizos e indios se logró una manera de clasificar la sociedad peruana). Esta diferenciación es visible además en el sistema educativo (en La ciudad y los perros se observa, específicamente, la desigualdad por clases sociales dentro del mismo colegio, como 
también en otras instituciones; además, son distinguidas por motivos educativos, económicos y hasta étnicos); además, se caracterizaba por ser elitista, por lo que la educación era un derecho de minorías cultas: la enseñanza estaba dirigida a una sociedad jerarquizante y excluyente (sectores altos y medios de la sociedad, y, en todo caso, a los grupos urbanos). Enrique Bernales (CARRILLO, 1993) observa, a partir de la novela, el conflicto entre la modernidad contra el carácter cerrado de su identidad, provocado por las necesidades de crecimiento y expansión demográficos.

Ante este tipo de ideología política excluyente y elitista, es notorio percatarse de una constante de reacciones sobre esas interacciones manifestadas por la desigualdad y la injusticia. Por ello, como segundo punto a tratar, para comprender el comportamiento humano de esa etapa, es necesario confrontar con las ideologías filosóficas imperantes; en este caso, el existencialismo y la fenomenología, los cuales tendrán una importancia en cuanto al quehacer literario de Mario Vargas Llosa.

El existencialismo, originado en el siglo XIX, se trata de aquella búsqueda de la libertad por sí misma, por lo que se recurre para ello a una postura ateísta (SARTRE, 2001), por la que se concebiría la idea de que Dios alcanzaría su propia muerte para justificar todas aquellas acciones individuales que generan angustia al ser humano, pero que se caracterizan por ser propias de su libre albedrío y su subjetividad, sin importar que recurra a la inmoralidad o el crimen. En la novela de Mario Vargas Llosa, hay un espacio en el que se hace patente la angustia en varios personajes, quienes están constantemente preocupados por cómo actuarían para sentirse partícipes de su propia humanidad (el Poeta debe delatar al verdadero asesino del Esclavo, el Jaguar debe aceptar el castigo que se le quiera imponer, los estudiantes del quinto año deben hacer justicia por sí solos hacia el Jaguar, quien supuestamente los ha delatado, etc.). Este tipo de experiencia revelaría que el hombre, al poseer un grado de libertad concebido, lo emplea para degradarse y no tanto para expresar su propia concepción de humanidad en una determinada época, que era el principio general del existencialismo (SARTRE, 2001, p.15). De alguna forma, la religión pondría un límite al compromiso libre del hombre, ya que si Dios no existiría todo estaría permitido, tal como lo señaló Fiódor Dostoievsky en algún momento (SARTRE, 2001, p. 7)

En la fenomenología, movimiento filosófico del siglo XX, ya no importará el exceso de libertad que pueda tener el hombre del mundo, tal como ocurría con el existencialismo, sino que se centrará sobre el planteamiento de Edmund Husserl, el cual se obtiene de su artículo "La idea de la fenomenología" (1907), que se refiere a la prevalencia que se le otorga a la experiencia pura por medio de los sentidos (las vivencias de cada persona, sin añadido alguno, como el de las teorías o las ciencias naturales, para que estas puedan analizarse y demostrarse de modo imparcial y descriptivista, debido a que no necesitan ser explicadas). Lo que conduciría a dedicarse exclusivamente a las esencias mismas de las cosas y las emociones. Vargas Llosa lo consigue a través de los monólogos de sus personajes, sin importar cuál de todos se aproxime más a la verdad; lo que predomina allí es cómo se narran y cuentan los hechos. Por otro lado, una postura similar a la de Husserl la emplea Martin Heidegger, que puede evidenciarse en su texto Ser y tiempo (1926), en el que plantea que el fenomenalismo sería un "estar en el mundo", percibido en la rutina del hombre con sus respectivas aptitudes, roles, proyectos e intenciones. Con ello, nuevamente retomamos $L a$ ciudad y los perros (1963), novela en la que el hábito y la rutina se observan en las constantes repeticiones de formalidades existentes para la educación, como los horarios de clases establecidos, o el amor, por lo que cada personaje mantiene su propia línea de pensamiento para adquirir la posesión del mismo.

\section{Las características del boom latinoamericano}

El boom latinoamericano, en un contexto sociocultural, empieza a desarrollarse a inicios de 1960, y se explaya hasta 1972 aproximadamente, según lo propone Ángel Rama (2005); este se caracterizaría por ser un fenómeno editorial que se conocía por la difusión de trabajos experimentales, con postulados que eliminaban los convencionalismos tradicionales de la literatura latinoamericana. La producción de esta narrativa latinoamericana fue propicia y masiva por las editoriales, que tomaban las novelas como productos culturales (RAMA, 2005, p. 174); por ejemplo, desde 1960 ya se contaba con la creación, en Cuba, de la Casa de las Américas (con su revista y las premiaciones que realizaba), editorial conducida por Alejo Carpentier, donde acudían y se refugiaban diversos escritores e intelectuales que publicaban obras en conjunto durante esos años. Fue su espacio para promoverse y difundir sus saberes, como lo evidencia la realización de los diversos tirajes de obras, a partir del contexto continental integrante. Desde esos inicios, empiezan a difundir sus obras literarias los siguientes autores: Ernesto Sábato publica Sobre héroes y tumbas (1961); Juan Carlos Onetti, El astillero (1961); y Gabriel García Márquez, El coronel no tiene quién le escriba (1961) — considérese que en 1962 se funda la revista argentina Primera Plana, medio que permitirá la difusión del boom literario en los medios, un año después-; también, Julio Cortázar publicará Historias de 
cronopios y de famas (1962); Carlos Fuentes, La muerte de Artemio Cruz (1962) y Aura (1962); Gabriel García Márquez, Los funerales de Mamá Grande (1962); y el argentino Manuel Mujica Láinez, Bomarzo (1962) —ese mismo año es aquel que sirvió al escritor peruano Mario Vargas Llosa ganar el Premio Biblioteca Breve (editorial Seix Barral) entregado por la escritura de La ciudad y los perros (1963), celebrada de manera trasatlántica (en España e Hispanoamérica)- . En España, en el año 1963, será publicada la primera novela de Vargas Llosa (la repercusión de este logro servirá como principal incentivo para el surgimiento y la difusión del boom).

Además de tener el mercado y la publicación de libros a favor de la modernización y la jerarquización de la actividad literaria, los textos empezaron a ser dirigidos hacia un público mayor, ya no tanto para gente especializada; por otro lado, los autores de esos libros eran más jóvenes. Entre ellos, tenemos a Mario Vargas Llosa (Perú), Julio Cortázar (Argentina), Gabriel García Márquez (Colombia), Carlos Fuentes (México) y otros más.

Hay una peculiaridad que resalta la narrativa de este período con la forma de escribir narrativa tradicionalmente. Donald Shaw (1999, pp. 244-245) alude a esta distinción al referirse a siete características que presenta la novela del boom, que rechazaría aspectos tradicionales; estas son las siguientes:

La primera es el tránsito de lo rural a lo urbano. De esta misma, se develaría la desaparición de la novela criollista o telúrica, con temática rural, junto con la incidencia del neoindigenismo de Miguel Ángel Asturias y José María Arguedas (SHAW, 1999, pp. 244-245). Por tal motivo, habría un afán modernizador, debido también al rechazo de modelos dominantes de la sociedad burguesa.

La segunda se trata de la subordinación de la novela "comprometida" y la emergencia de la novela "metafísica". En vez de mostrar la injusticia y la desigualdad sociales con el propósito de criticarlas, la novela tiende a explorar la condición humana y la angustia del hombre contemporáneo, con la intención de buscar nuevos valores (SHAW, 1999, pp. 244-245). Muchos escritores del boom latinoamericano se cuestionan sobre la identidad y el destino de América, las que hacían que ellos se configuraran como intelectuales comprometidos de izquierda. Esta postura tendía a crear una firme resistencia ante el poder político y económico del capitalismo; y, para poder lograr esta manifestación, los grupos izquierdistas tuvieron que buscar filiaciones en torno a la revolución socialista, como medio para la transformación de la sociedad. Es en ese momento que la producción de novelas alcanza un espacio real y diferenciado, con un marco más completo de la experiencia de la vanguardia. Los escritores del boom adoptan este género literario como un instrumento de organización y revelación, ya que esta devela lo oculto, además de que su representación escrita es un acto de "construcción de construcción", por lo que permite indagar el panorama de la situación nacional (el compromiso): se postula la complejidad de un país o una nación.

La tercera está compuesta por la fantasía creadora y la mitificación de la realidad (SHAW, 1999, pp. 244-245). Aquella implicaba el distanciamiento de los escenarios realistas de la novela tradicional, los cuales eran remplazados por espacios imaginarios y la creación de un proyecto totalizador. En algunos casos, era necesario destacar la mímesis de la historia en la narrativa para una indagación nacional más amplia y panorámica, en esta se resaltaba la importancia de lo histórico y lo social, por lo que la realidad se presentaba como más próxima y compleja a la vez. Marina Gálvez Acero (1992, p. 53) observa la preferencia por representar el objeto de manera ensimismada, motivo por el que se unifican los géneros literarios, como la poesía con la novela; además, se excluye la anécdota en la narración.

La cuarta es el énfasis en los aspectos ambiguos, irracionales y misteriosos de la realidad, junto con la personalidad, que confluirían en lo absurdo, como metáfora de la existencia humana (SHAW, 1999, p. 244245). Para ello, se emplearán elementos simbólicos con mayor énfasis, por los que la concepción de la realidad se expande y se complementa con mitos o universos oníricos. Para que este punto lograse su veracidad, servía tener en cuenta una conciencia estética sobre la base de las estructuras lingüísticas; es decir, surgieron diversas experimentaciones verbales, con la finalidad de representar la variedad de hablas y dialectos de las personas. Marina Gálvez Acero (1992, p.53) indicaba que este era un medio para hallar una identidad cultural, única. Aquello ocurre, por ejemplo, con la búsqueda de la identidad por parte de Gabriel García Márquez o el constante abordaje descriptivo de Alejo Carpentier.

La quinta abarca la tendencia a desconfiar del concepto del amor como soporte existencial y de enfatizar, en cambio, la incomunicación y la soledad del individuo. Cabe mencionar, pues, el intenso antirromanticismo de la nueva novela (SHAW, 1999, p. 244-245).

La sexta alude a la necesidad de quitar valor al concepto de la muerte en un mundo que es, ya de por sí, caracterizado por ser una sociedad degradada en valores (SHAW, 1999, p. 244-245).

La séptima es la rebelión contra toda forma de tabúes morales, por la que la temática de lo público y lo privado entran en conflicto, sobre todo, los vínculos con la religión y la sexualidad, junto con la tendencia paralela a introducirse en las visiones demenciales, que provienen de las vidas secretas. 
Considerando que estas características fueron importantes para demarcar la nueva concepción de novela que tuvieron los escritores del boom, se toman en cuenta los recursos estilísticos que se emplearon, con los cuales se buscaba el afán experimental y a lo que Ángel Rama (2005, p. 163) llama técnicas vanguardistas europeas e imágenes enajenadas de la realidad de un continente; estos, según Donald Shaw (1999, pp. 244-245), fueron los siguientes: las técnicas influenciadas por el cine (close up, flashback, etc.), las técnicas de contrapunto, el desdoblamiento de las cosas (fragmentación, multiplicidad o simultaneidad de planos, espacios, mentes, personajes y narradores), los múltiples puntos de vista, el empleo del monólogo interior, los vasos comunicantes, las cajas chinas (o el relato dentro del relato) y la ruptura de la línea argumental. Todas estas tenían la intención de buscar una relación empática del autor con el lector, por lo que se consideraba a este último como un nuevo público receptor, formado por la educación universitaria, que se encuentra lo suficientemente preparado para discernir las múltiples posibilidades de lectura e interpretación que tendrá una novela del boom, como también de organizar las complejas estructuras narrativas que le atribuye el autor; por ejemplo, en Rayuela (1963), se postula la lectura del tablero, como también múltiples posibilidades de acceso, por lo que se infiere que el lector es una especie de autor y protagonista a la vez.

\section{La ciudad y los perros (1963)}

Es la primera novela del escritor peruano Mario Vargas Llosa, esta hace una alusión al marino Leoncio Prado Gutiérrez, representante militar que fue fusilado por las tropas chilenas durante la Guerra del Pacífico de 1879, cuyo nombre designaba el nombre del Colegio Militar, lugar donde se desarrollan los hechos. Originalmente, el autor la designó como La morada del héroe y, luego, Los impostores, título que figuró en las informaciones sobre el fallo y que provenía del epígrafe sartreano que lleva la novela, pero que el autor abandonó después, porque podía hacer pensar en una narración de corte policial o misterio. Meses después, decidió intitularla, definitivamente, $\mathrm{La}$ ciudad y los perros (1963), el nombre definitivo no lo puso el propio autor, sino Carlos Barral (OVIEDO, 2007, p.66). Su publicación se efectúa recién en 1963, a la vez que se le otorga el Premio de la Crítica Española; al realizarse la publicación, Vargas Llosa apareció como el miembro más joven de los novelistas representativos del boom (OVIEDO, 2007, p.54), ya que para ese entonces contaba con solo veintisiete años.

La importancia de La ciudad y los perros (1963) es trascendental, pues aperturó una nueva manera de analizar la modernidad en la narrativa peruana. A la par, con otras obras de diversos autores de Latinoamérica, inició el boom. Para José María Valverde (ARMAS, 2008), esta novela era la más sólida que se había escrito en castellano, luego de Don Segundo Sombra (1926).

Hasta ahora, esta novela de Vargas Llosa ha tenido múltiples ediciones y ha sido traducida a diversos idiomas. Su título en lengua inglesa es conocido como The time of the hero. Una adaptación cinematográfica de la misma ya ha sido estrenada en el Perú en 1985, la cual fue dirigida por el director de cine peruano Francisco José Lombardi, con el guion escrito por el mismo Mario Vargas Llosa junto a José Watanabe.

La ciudad y los perros (1963) está ambientada en el Colegio Militar Leoncio Prado, donde se narran episodios de las vivencias de los alumnos de la escuela militar (Alberto Fernández —el Poeta—, el Jaguar, Ricardo Arana - el Esclavo-, el serrano Cava, el Boa, el Rulos, el brigadier Arróspide y el negro Vallano), dentro y fuera de la misma. La novela empieza a tener importancia a partir del robo del cuestionario de un examen de Química, el cual conduce a un trágico desenlace luego del descubrimiento del culpable (serrano Cava): el asesinato del acusador (el Esclavo), por parte del presunto asesino (el Jaguar), quien cometería este homicidio para compensar la delación con la muerte.

\section{Consideraciones finales}

La ciudad y los perros (1963) surgió de un contexto caracterizado por la presencia militar, junto con las ideologías filosóficas del existencialismo (Sartre) y la fenomenología (Husserl); a su vez, desarrolla elementos propios del boom latinoamericano, como el afán de incorporar técnicas narrativas innovadoras.

\section{Referencias}

ARMAS, Juan Jesús. Vargas Llosa: el vicio de escribir. Barcelona: Debolsillo, 2008.

AUERBACH, Erich. Mímesis. La representación de la realidad en la literatura occidental. México, DF: Fondo de Cultura Económica, 1996. https://doi.org/10.4067/s071822012014000200020

CARRILLO, José Luis. (ed.). Violencia en la región andina: caso Perú. Lima: Asociación Peruana de Estudios e Investigación para la Paz (Apep), 1993. https://doi. org/10.21678/apuntes.27.319

GÁLVEZ, Marina. La novela hispanoamericana contemporánea. Madrid: Taurus, 1992.

GORRITI, Gustavo. Sendero. Historia de la Guerra Milenaria en el Perú. I. Lima: Apoyo, 1991. https://doi. org/10.2307/20044633 
HEIDEGGER, Martín. Ser y tiempo. 1953 (1926). 7.ed.

Trad. J. Rivera. Disponível em: https://goo.gl/vxrgnt.

HUSSERL, Edmund. La idea de la fenomenología. (1907).

[2010]. Disponível em: http://biblio3.url.edu.gt/Libros/joyce/ idea.pdf.

OVIEDO, José Miguel. Dossier. Vargas Llosa. Lima: Taurus, 2007.

RAMA, Ángel. El boom en perspectiva. Signos Literarios 1, 2005, p. 161-208, enero-junio, 1984.

SARTRE, Jean Paul. El existencialismo es un humanismo. 2001. Disponível em: http://www.uruguaypiensa.org.uy/ imgnoticias/766.pdf.

SHAW, Donald. Nueva narrativa hispanoamericana: Boom, Posboom, Posmodernismo. 6. ed. Madrid: Cátedra, 1999.

TENORIO, Néstor. Mario Vargas Llosa. El fuego de la literatura. Lima: Arteidea Editores, 2001.

VARGAS, Mario. La ciudad y los perros. Edición conmemorativa del cincuentenario. Italia: Alfaguara, Real Academia Española, 2012 (1963).

VILELA, Sergio. El cadete Vargas Llosa: la historia oculta tras "La ciudad y los perros". Santiago de Chile: Planeta, 2003.

Recibido en: 22/03/2018.

Aprobado en: 26/03/2019.

Publicado en: 26/06/2019.

\section{Autor:}

Jesús Miguel Delgado Del Aguila

Orcid: https://orcid.org/0000-0002-2633-8101

E-mail: tarmangani2088@outlook.com

Enderezo: Facultad de Humanidades - Sede central

Avenida Arequipa 265 - Cercado de Lima

Lima, Perú 